\title{
Outward transport of fluorescein from the vitreous in aphakic eyes
}

\author{
KENSAKU MIYAKE, TAKEKO MIYAKE, CHIKAKO MIYAKE, \\ MASAKO ASAKURA, AND KUMIKO MAEKUBO \\ From the Shohzankai Medical Foundation, Miyake Eye Clinic Hospital, Nagoya, Japan
}

SUMMARY By administering fluorescein intravenously to 95 patients we calculated the ratio of fluorescein concentration in the vitreous at the time of its peak level compared with the estimated unbound concentration of fluorescein in the plasma at the same time. We studied 12 normal phakic and 83 aphakic eyes approximately two months, one year, and more than two years after cataract extraction. All the eyes had undergone intracapsular cataract extraction or extracapsular cataract extraction, with or without posterior capsulotomy, because of senile cataract. The calculated ratio in patients with intracapsular and extracapsular lens extraction was statistically significantly reduced at two months and one year after cataract extraction and was normalised at more than two years after the operation in comparison with normal subjects. The ratio was statistically significantly reduced in patients with intracapsular extraction compared with those with extracapsular extraction at two months and one year after surgery. Posterior capsulotomy had no effect on the ratio. The ratio, we considered, at least partially reflects the outward transport of fluorescein from the vitreous cavity. Although the findings reflect subclinical phenomena, they are of importance when considering postoperative sequelae. The posterior lens capsule, zonule, and intact anterior vitreous face may be essential for the anterior uvea to function in the outward transport of fluorescein from the vitreous cavity.

Recently the basic surgical technique in cataract extraction has been changing from intracapsular to extracapsular, because with the extracapsular method there is a lower incidence of such postoperative complications as cystoid macular oedema, vitreous changes, and retinal detachment. ${ }^{12}$ Although an intact posterior lens capsule postoperatively has been regarded as essential in preventing these complications, its biological significance is unknown.

Worst ${ }^{3}$ has postulated that the aqueous becomes biotoxic after cataract extraction, and stressed the significance of the intact posterior lens capsule and vitreous as a protective factor against aphakic cystoid macular oedema. Ozaki ${ }^{4}$ has stated that the posterior lens capsule may serve as a diffusion barrier of some substances. A common feature of these hypotheses is that, when the posterior lens capsule is lost after intracapsular cataract extraction, substances in the

Correspondence to Dr K Miyake, Shohzankai Medical Foundation, Miyake Eye Clinic Hospital, 1070-Kami 5, Higashiozone-cho, Kitaku, Nagoya, Japan 462 . aqueous penetrate more easily into the vitreous cavity and affect the retina.

More recently Binkhorst ${ }^{\prime}$ explained the postoperative disorders following intracapsular cataract extraction by the term 'barrier deprivation syndrome. " $\mathrm{He}$ suggested that intracapsular cataract extraction deprives the eye of the stabilising effect of the lenszonule barrier and causes loss of stability inside the eye-namely, endophthalmodonesis, whose mechanical aspects may be the cause of postoperative complications. The biological nature of this mechanical aspect is unknown.

Studies with fluorophotometry have shown a disruption of the blood-retinal barrier following lens extraction that was greater after intracapsular than after extracapsular extraction. ${ }^{56}$ These authors have considered that the high concentration of fluorescein in the vitreous is mainly due to hyperpermeability of the dye from the blood to the vitreous. Is that assumption true? Fluorescein is actively transported from the vitreous into the blood, ${ }^{78}$ and this function seems to be disturbed in some pathological con- 
ditions. ${ }^{9-11}$ Furthermore, Blair and associates ${ }^{12}$ have recently demonstrated in healthy persons that the outward permeability to fluorescein was approximately 30 times the inward permeability. Exchange of the dye between the vitreous and the blood occurs across several cellular layers, which constitute the blood-vitreous barrier. These layers include the retinal pigment epithelium, retinal vascular endothelium, non-pigmented ciliary epithelium, and irideal pigment epithelium. ${ }^{7813-15}$ Among the sites of the function the non-pigmented ciliary epithelium and the irideal pigment epithelium are in the vicinity of the lens; they are assumed to be influenced by surgical traumas of lens extraction and also by whether or not the posterior lens capsule remains intact in the postoperative eye.

We measured the ratio between the outward and inward coefficients of permeability to fluorescein in normal subjects, and in subjects who underwent intracapsular cataract extraction, extracapsular cataract extraction, and extracapsular cataract extraction with posterior capsulotomy. We discuss here the possible role of the posterior lens capsule, especially its relationship to the active transport of fluorescein from the vitreous cavity.

\section{Subjects and methods}

\section{SUBJECTS}

At approximately two months, one year, and more than two years (average of 3.9 years) after cataract extraction we randomly selected 20 cases each that underwent intracapsular and extracapsular procedures, and 15 cases that underwent extracapsular extraction and posterior capsulotomy at one session by cystotome or immediately after original surgery by YAG (yttrium-aluminium-garnet) laser. The capsulotomy was not large enough to allow a large amount of the vitreous to herniate into the anterior chamber. All the subjects underwent the operation because of senile cataract. The subjects examined at the three time periods were not the same. All patients were told the nature of the study, and all gave their informed consent.

We then excluded from the study cases that had operative complications such as vitreous loss or endophthalmitis, and ocular disorders associated with disruption of the blood retinal barrier such as uveitis, systemic hypertension requiring therapy, diabetes mellitus, pigmentary retinal dystrophy, and degenerative myopia. Patients under 55 years old and those who had disorders of the kidney or liver, or who could not come for the examinations, were also excluded from the study. Twelve normal volunteers over 55 years old were included in the study. The distribution of cases and eyes that were actually
Table 1 Distribution of eyes studied

\begin{tabular}{llllll}
\hline Group & $\begin{array}{l}\text { Time } \\
\text { after } \\
\text { operation }\end{array}$ & $\begin{array}{l}\text { No. of Age range } \\
\text { eyes }\end{array}$ & $\begin{array}{l}\text { Average age } \\
(y r)\end{array}$ & $\begin{array}{l}\text { Number } \\
\text { and } \\
\text { sex }\end{array}$ \\
\hline Normal & & 12 & $57-70$ & $67 \cdot 21 \pm 7 \cdot 14$ & $5 \mathrm{M} / 7 \mathrm{~F}$ \\
ICCE $^{*}$ & $2 \mathrm{mo}$ & 13 & $56-74$ & $68 \cdot 39 \pm 6 \cdot 19$ & $5 \mathrm{M} / 8 \mathrm{~F}$ \\
ECCE $^{*}$ & $2 \mathrm{mo}$ & 15 & $55-79$ & $66 \cdot 34 \pm 8 \cdot 21$ & $5 \mathrm{M} / 10 \mathrm{~F}$ \\
ECCE.PC* $^{*}$ & $2 \mathrm{mo}$ & 11 & $55-79$ & $65 \cdot 76 \pm 5 \cdot 46$ & $6 \mathrm{M} / 5 \mathrm{~F}$ \\
ICCE & $1 \mathrm{yr}$ & 11 & $60-80$ & $69 \cdot 34 \pm 6 \cdot 62$ & $6 \mathrm{M} / 5 \mathrm{~F}$ \\
ECCE & $1 \mathrm{yr}$ & 12 & $55-80$ & $67 \cdot 82 \pm 7 \cdot 52$ & $5 \mathrm{M} / 7 \mathrm{~F}$ \\
ICCE & $>2 \mathrm{yr}$ & 11 & $55-74$ & $67 \cdot 44 \pm 6 \cdot 51$ & $6 \mathrm{M} / 5 \mathrm{~F}$ \\
ECCE & $>2 \mathrm{yr}$ & 10 & $58-76$ & $64 \cdot 52 \pm 7 \cdot 32$ & $5 \mathrm{M} / 5 \mathrm{~F}$ \\
\hline
\end{tabular}

${ }^{*}$ ICCE, intracapsular cataract extraction; ECCE, extracapsular cataract extraction; ECCE.PC, extracapsular cataract extraction with posterior capsulotomy.

studied is shown in Table 1. There were no statistically significant differences among the groups.

\section{METHODS}

The theoretical basis of the methodology is the same as described by Blair and associates. ${ }^{12}$ The new aspect in this study is that fluorescein was administered intravenously. To measure the fluorescein concentration in the vitreous, we used commercially available fluorophotometers ${ }^{13-18}$ (Fluorotron Master, Coherent Co., CA, and Gamma-Inami Fluorophotometer, Inami Co., Tokyo, Japan). During the examination with the Fluorotron Master, which is also capable of measuring fluorescein concentrations in the serum, aphakic patients wore glasses or contact lenses, and all patients were examined under a fully mydriatic pupil.

Each subject was given $10 \mathrm{mg} / \mathrm{kg}$ sodium fluorescein intravenously. Fluorescein fundus angiography was done to detect cystoid macular oedema. Vitreous fluorophotometry was performed hourly for seven or eight hours, in most cases starting one hour after the patient received the fluorescein by the method described previously. ${ }^{1718}$ From the results of serial fluorophotometry we recognised the peak concentration of fluorescein in the mid vitreous $(9$ $\mathrm{mm}$ from the retina) $(\mathrm{Cv})$ and the time of the peak concentration. Blood was obtained from a finger prick both at one hour after administration of fluorescein and at the end of the measurement series. The total blood concentration was also measured by fluorophotometry and was plotted as a function of time. The value at the time of maximum $\mathrm{Cv}(\mathrm{Ct})$ was interpolated according to an exponential decline. Then the concentration of unbound fluorescein in the serum at time $\mathrm{t}(\mathrm{Cs})$ was calculated from the following equation, as described by Blair and associates ${ }^{12}$ :

$$
\mathrm{Cs}=\% \mathrm{UCt} / 100-\mathrm{Hct},
$$

where $\% \mathrm{U}$ is the percentage of unbound fluorescein 
in the serum (as \%U, $17.5 \%$ was used according to the results by Araie et al. ${ }^{14}$ ) and Hct is the haematocrit ( $45 \%$ for males, $40 \%$ for females). In some cases the Cs was measured by the above procedures and in the remainder the Cs was directly measured by ultrafiltration using membrane cone (MPS-3, Amicon Co., Tokyo, Japan) at the time of the measurement of the total blood concentration, and was plotted as a function of time. Ct was interpolated according to an exponential decline. To find the difference in the mixing rate at the long term reading between the aqueous and vitreous fluorescein among the groups we measured the ratio of the concentration of fluorescein in the aqueous (centre of the anterior chamber) at the time of maximum $\mathrm{Cv}\left(\mathrm{C}_{\mathrm{A}}\right)$ and $\mathrm{Cv}$.

\section{Results}

Table 2 gives the time of peak $\mathrm{Cv}, \mathrm{Cv}, \mathrm{Ct}, \mathrm{Cs}, \mathrm{Cs} / \mathrm{Cv}$, and $\mathrm{C}_{\mathrm{A}} / \mathrm{Cv}$ for each group at the three time periods. At two months and at one year after the operation the $\mathrm{Cs} / \mathrm{Cv}$ ratio was statistically significantly lower in all groups except the extracapsular group at 1 year that underwent cataract extraction than in normal subjects $(p<0.01-p<0.05)$, and was statistically significantly lower in intracapsular than in extracapsular extraction groups $(p<0.05)$. There was no statistically significant difference in the $\mathrm{Cs} / \mathrm{Cv}$ ratio between the group given extracapsular extraction and the group given extracapsular extraction with posterior capsulotomy $(p<0.5)$. More than two years after the operation there was no statistically significant difference in the $\mathrm{Cs} / \mathrm{Cv}$ ratio between the intracapsular extraction and extracapsular extraction groups $(p>0.5)$, between the normal and intracapsular groups ( $>00.5)$, and between the normal and extracapsular groups $(p<0 \cdot 3)$. There was no statistically significant difference in the $\mathrm{Ca} / \mathrm{Cv}$ ratio among the groups studied $(p<0 \cdot 5)$.
Cystoid macular oedema was detected in five eyes of the intracapsular extraction group and six eyes of the extracapsular extraction group at two months after the operation, and was detected in one eye of the intracapsular extraction group at one year after the operation. Although these cases had low $\mathrm{Cs} / \mathrm{Cv}$ ratios, no statistical analysis could be done because of the small number of subjects.

\section{Discussion}

The Cs/Cv ratio reflects many biological phenomena, including the function of the blood vitreous barrier (inward and outward permeability of fluorescein), intraocular diffusion of fluorescein, metabolic factors of sodium fluorescein (fluorescein gluculonide), and others, but it mainly indicates the outward transport of fluorescein. ${ }^{12}$

The outward transport of fluorescein from the vitreous in aphakic eyes with apparently normal fundus was lowered until at least one year postoperatively, and was lower after intracapsular than after extracapsular cataract extraction. These results are noteworthy when one considers the biology of lens extraction procedures and the pathogenesis of postoperative complications.

Miyake,${ }^{56}$ examining longstanding aphakic eyes by means of vitreous fluorophotometry, has reported an abnormally high concentration of fluorescein and a more persistent disruption of the blood retinal barrier than expected. He found a higher incidence of this disruption in aphakic eyes after intracapsular than after extracapsular cataract extraction. What is the true nature of this barrier disruption? In the present study we have shown that the persistently high concentration of fluorescein in the vitreous is partly due to the reduction of outward transport. The active transport system to sodium fluorescein inside the eye is located in the retinal pigment epithelium,

Table 2 Fluorescein concentrations in serum and vitreous

\begin{tabular}{|c|c|c|c|c|c|c|c|c|}
\hline \multirow[t]{2}{*}{ Group } & \multirow{2}{*}{$\begin{array}{l}\text { Time } \\
\text { after } \\
\text { operation }\end{array}$} & \multirow{2}{*}{$\begin{array}{l}\text { Time of peak } \\
C v, \text { hours } \\
(m e a n \pm S D)\end{array}$} & \multirow[t]{2}{*}{$\begin{array}{l}C v n g / m l \\
(m e a n \pm S D)\end{array}$} & \multirow[t]{2}{*}{$\begin{array}{l}\text { Ctng/ml } \\
(m e a n \pm S D)\end{array}$} & \multirow{2}{*}{$\begin{array}{l}\text { Estimated } \\
C s, n g / m l \\
(m e a n \pm S D)\end{array}$} & \multirow[t]{2}{*}{$\begin{array}{l}C s / C v \\
(m e a n \pm S D)\end{array}$} & \multirow[t]{2}{*}{$\begin{array}{l}C a / C v \\
(m e a n \pm S D)\end{array}$} & \multirow{2}{*}{$\begin{array}{l}\begin{array}{l}\text { Statistical significance } \\
\text { of } C s / C v(t \text { test })\end{array} \\
\text { v. Normal ICCE v. ECCE }\end{array}$} \\
\hline & & & & & & & & \\
\hline Normal & & $5.42 \pm 1.44$ & $15.64 \pm 3.48$ & $1135 \cdot 60 \pm 575.04$ & $347 \cdot 83 \pm 176 \cdot 63$ & $27.45 \pm 19.63$ & $1.36 \pm 0.44$ & \\
\hline $\mathrm{ICCE}^{*}$ & $2 \mathrm{mo}$ & $6 \cdot 08 \pm 1 \cdot 32$ & $44 \cdot 62 \pm 24 \cdot 48$ & $1414 \cdot 54 \pm 494 \cdot 19$ & $396 \cdot 23 \pm 153 \cdot 79$ & $9.06 \pm 5.06$ & $1.42 \pm 0.63$ & $\mathrm{p}<0.01$ \\
\hline $\mathrm{ECCE}^{*}$ & $2 \mathrm{mo}$ & $6 \cdot 33 \pm 1 \cdot 80$ & $29.00 \pm 12.93$ & $1245 \cdot 67 \pm 266 \cdot 34$ & $389 \cdot 60 \pm 85 \cdot 19$ & $13 \cdot 73 \pm 5 \cdot 90$ & $1 \cdot 51 \pm 0.52$ & $\mathrm{p}<0.05$ ) \\
\hline ICCE & $1 \mathrm{yr}$ & $6.64 \pm 0.92$ & $32 \cdot 91 \pm 9 \cdot 60$ & $1203 \cdot 73 \pm 340 \cdot 88$ & $365 \cdot 91 \pm 105 \cdot 86$ & $11 \cdot 54 \pm 3 \cdot 35$ & $1.53 \pm 0.52$ & $\mathrm{p}<0.02$ \\
\hline ECCE & $1 \mathrm{yr}$ & $5 \cdot 75 \pm 1.06$ & $24 \cdot 43 \pm 8 \cdot 33$ & $1385 \cdot 25 \pm 388 \cdot 74$ & $391 \cdot 62 \pm 98 \cdot 82$ & $15 \cdot 74 \pm 4 \cdot 34$ & $1.43 \pm 0.62$ & $p<0.1$ \\
\hline ICCE & $>2 \mathrm{yr}$ & $5 \cdot 82 \pm 0 \cdot 87$ & $16 \cdot 18 \pm 7 \cdot 80$ & $1209 \cdot 36 \pm 308 \cdot 80$ & $372 \cdot 09 \pm 105 \cdot 12$ & $27 \cdot 34 \pm 11 \cdot 69$ & $1.39 \pm 0.62$ & $p>0.5$ \\
\hline $\mathrm{ECCE}$ & $>2 \mathrm{yr}$ & $5 \cdot 80 \pm 1.03$ & $17 \cdot 00 \pm 9.01$ & $1201 \cdot 70 \pm 253 \cdot 01$ & $373 \cdot 60 \pm 85 \cdot 96$ & $27 \cdot 45 \pm 19.63$ & $1.45 \pm 0.26$ & $\mathrm{p}<0.3\}$ \\
\hline
\end{tabular}

*ICCE, intracapsular cataract extraction; ECCE, extracapsular cataract extraction; ECCE.PC, extracapsular cataract extraction with posterior capsulotomy. tp $>0.5$. 
retinal vascular endothelium, ciliary non-pigment epithelium, and iris pigment epithelium. ${ }^{7813-15}$ The anatomical or topographical difference in postoperative aphakic eyes following intracapsular and extracapsular cataract extraction is the existence of a posterior lens capsule and, in the former eyes, changes in the anterior vitreous face.

It is interesting to discuss the relationship between the site of active fluorescein transport and the anatomical and biological differences between the two basic procedures of cataract extraction. We assume that the ciliary non-pigment epithelium and the iris pigment epithelium may be protected from intra- and postoperative surgical injury by an intact posterior lens capsule. Actually, during extracapsular cataract extraction the ciliary body may be much less impaired through the zonule than it is in the intracapsular procedure, and postoperatively the posterior lens capsule may protect the anterior uvea from the mechanical and physical irritations of the vitreous gel.

In the present communication we have further demonstrated that planned and small posterior capsulotomy (as performed by YAG laser) did not significantly reduce the biological superiority of aphakic eyes that underwent extracapsular cataract extraction. Binkhorst has given the name 'barrier deprivation syndrome' to complications in aphakic eyes following intracapsular cataract extraction. ${ }^{1}$ Although the true nature of this syndrome, especially the mechanism of barrier deprivation, is unknown, we consider that the dysfunction of active transport of fluorescein found in aphakias following intracapsular cataract extraction may point to the essential aspect of the barrier deprivation. It is therefore promising to consider the pathogenesis of postoperative complications, especially cystoid macular oedema, along the lines of the present findings.

Recent studies suggest that aphakic cystoid macular oedema is related to intraocular prostaglandin biosynthesis. ${ }^{24-22}$ Normally prostaglandins are rapidly removed from intraocular fluid by the active transport mechanism of the anterior uvea. ${ }^{23}$ It has also been shown that potentially harmful or nonphysiological substances such as fluorescein, cyclic AMP, antibiotics, and prostaglandins are removed in a similar manner inside the eye..$^{24}$ The present results indicate that the active transport of fluorescein is more impaired after intracapsular than extracapsular cataract extraction. It is widely accepted that the incidence of cystoid macular oedema is higher after intracapsular than extracapsular extraction. ${ }^{2}$ From this evidence we conclude that aphakic cystoid macular oedema is closely related to dysfunction of the active transport mechanism. The number of cases with cystoid macular oedema in this study was too small to analyse; however, we are now conducting studies along these lines.

Some controversies surround the method of calculation we used. ${ }^{12}$ However, here we discuss the chronological time course of posterior vitreous fluorescein concentration and serum-free fluorescein concentration. Near the time of peak $\mathrm{Cv}$ the vitreous fluorescein concentration does not noticeably change, and it even shows plateaux ${ }^{25}$ in a small number of cases, whereas the serum fluorescein concentration decreases gradually. This change could cause substantial change in the $\mathrm{Cs} / \mathrm{Cv}$ calculation. However, since this phenomenon is observed in both normal and pathological eyes, it probably does not influence the trends of this study.

\section{References}

1 Binkhorst $\mathrm{C}$. Corneal and retinal complications after cataract extraction. The mechanical aspect of endophthalmodonesis. Ophthalmology 1980; 87: 609-17.

2 Miami Study Group. Cystoid macular edema in aphakic and pseudophakic eyes. Am J Ophthalmol 1979; 88: 45-8.

3 Worst JGF. Biotoxität des Dammerwassers. Klin Monatsbl Augenheilkd 1975; 167: 376-81.

4 Ozaki L. The barrier function of the posterior capsule. Am Intraocular Implant Soc J, 1984; 10: 182-4.

5 Miyake K. Blood-retinal barrier in eyes with long-standing aphakia with apparently normal fundi. Arch Ophthalmol 1972; 100: $1437-9$.

6 Miyake K. Blood-retinal barrier in longstanding aphakic eyes after extra- and intracapsular lens extraction. Graefes Arch Klin Exp Ophthalmol 1985; 222: 232-3.

7 Cunha-Vaz JG, Maurice DM. The active transport of fluorescein by the retinal vessels and the retina. J Physiol (Lond) 1967; 191: 467-86.

8 Cunha-Vaz JG, Maurice DM. Fluorescein dynamics in the eye. Doc Ophthalmol 1969; 26: 61-72.

9 Jones CW, Cunha-Vaz JG, Zweig KO, Stein M. Kinetic vitreous fluorophotometry in experimental diabetes. Arch Ophthalmol 1979; 97: 1941-3.

10 Krupin T, Waltman SR, Szewczyk P, et al. Fluorometric studies on the blood-retinal barrier in experimental animals. Arch Ophthalmol 1982; 100: 631-4.

11 Anstadt B, Blair NP, Rusin MM, et al. Alteration of the bloodretinal barrier by sodium iodate: kinetic vitreous fluorophotometry and horseradish peroxidase tracer studies. Exp Eye Res 1982; 35: 653-62.

12 Blair NP, Zeimer RC, Rusin MM, Cunha-Vaz JG. Outward transport of fluorescein from the vitreous in normal human subjects. Arch Ophthalmol 1983; 101: 1117-21.

13 Shiose Y, Sears ML. Fine structural localization of nucleoside phosphatase activity in the ciliary epithelium of albino rabbits. Invest Ophthalmol Visual Sci 1966; 5: 152.

14 Mazima T. Studies on retinitis pigmentosa. Part 22. Electronmicroscopic observations of retinal 'ATP' are in experimental retinal degeneration treated with sodium iodate. Nippon Ganka Gakkai Zasshi 1966; 70: 1424-41.

15 Maurice DM. The use of fluorescein in ophthalmological research. The Jonas S Friedenwald Memorial Lecture. Invest Ophthalmol Visual Sci 1967; 6: 464-77.

16 Cunha-Vaz JG, Goldberg MF, Vygantas C, Noth J. Early detection of retinal involvement in diabetes by vitreous fluorophotometry. Trans Am Acad Ophthalmol Otolaryngol 1979; 86: 264-76.

17 Zeimer RC, Blair NP, Cunha-Vaz JG. Vitreous fluorophotometry for clinical research: I. Description and evaluation of a 
new fluorophotometer. Arch Ophthalmol 1983; 101: 1753-6.

18 Zeimer RC, Blair NP, Cunha-Vaz JG. Vitreous fluorophotometry for clinical research: II. Method of data acquisition and processing. Arch Ophthalmol 1983; 101: 1757-61.

19 Araie M, Sawa M, Nagataki S, et al. Aqueous humor dynamics in man as studied by oral fluorescein. Jpn J Ophthalmol 1980; 24: 346-62.

20 Miyake K, Sakamura S, Miura H. Long-tern follow-up study on prevention of aphakic cystoid macular oedema by topical indomethacin. Br J Ophthalmol 1980; 64: 324-8.

21 Yannuzzi LA, Landau AN, Turtz AI. Incidence of aphakic cystoid macular edema with the use of topical indomethacin. Ophthalmology 1981; 88: 947-54.
22 Kraff MC, Sanders DR, Jampol LM, et al. Prophylaxis of pseudophakic cystoid macular edema with topical indomethacin. Ophthalmology 1982; 89: 885-90.

23 Bito LZ, Salvador EV. Intraocular fluid dynamics. III. The site and mechanism of prostaglandin transfer across the blood intraocular fluid barriers. Exp Eye Res 1972; 14: 233-41.

24 Bito LZ, DeRousseau CJ. Transport functions of the bloodretinal barrier system and the micro-environment of the retina. In: Cunha-Vaz JG, ed. The blood-retinal barriers. NATO Advanced Study Institutes Series. New York and London, Plenum Press, 1979; 32: 133-63.

25 Palestine AG, Brubaker RF. Pharmacokinetics of fluorescein in the vitreous. Invest Ophthalmol Visual Sci 1981; 21: 542-9. 